\title{
Surface Quality Improvement in Machining an Aluminum Honeycomb by Ice Fixation
}

\author{
Yongqing Wang, Yongquan Gan, Haibo Liu*, Lingsheng Han, Jinyu Wang and Kuo Liu
}

\begin{abstract}
A honeycomb structure is widely used in sandwich structure components in aeronautics and astronautics; however, machining is required to reveal some of its features. In honeycomb structures, deficiencies, such as burrs, edge subsiding, and cracking, can easily appear, owing to poor specific stiffness in the radial direction. Some effective fixation methods based on a filling principle have been applied by researchers, including approaches based on wax, polyethylene glycol, iron powder, and (especially) ice. However, few studies have addressed the optimization of the cutting parameters. This study focused on optimizing the cutting parameters to obtain a better surface roughness (calculated as a roughness average or $R_{a}$ ) and surface morphology in the machining of an aluminum alloy honeycomb by an ice fixation method. A Taguchi method and an analysis of variance were used to analyze the effects and contributions of spindle speed, cutting depth, and feed rate. The optimal cutting parameters were determined using the signal-to-noise ratio combined with the surface morphology. An F-value and P-value were calculated for the value of the $R_{a^{\prime}}$ according to a "smaller is better" model. Additionally, the optimum cutting parameters for machining the aluminum honeycomb by ice fixation were found at different levels. The results of this study showed that the optimal parameters were a feed rate of $50 \mathrm{~mm} / \mathrm{min}$, cutting depth of $1.2 \mathrm{~mm}$, and spindle speed of $4000 \mathrm{r} / \mathrm{min}$. Feed rate was the most significant factor for minimizing $R_{\mathrm{a}}$ and improving the surface morphology, followed by spindle speed. The cutting depth had little effect on $R_{\mathrm{a}}$ and surface morphology. After optimization, the value of $R_{\mathrm{a}}$ could reach $0.218 \mu \mathrm{m}$, and no surface morphology deterioration was observed in the verified experiment. Thus, this research proposes optimal parameters based on ice fixation for improving the surface quality.
\end{abstract}

Keywords: Honeycomb, Ice fixation, Cryogenic milling, Surface roughness, Surface morphology, Optimal parameters

\section{Introduction}

A honeycomb structure is widely used in aeronautics and astronautics, owing to its high stiffness-to-weight ratio, good rigidity, shock resistance, and superior insulation qualities $[1,2]$. It is especially useful in large components such as spacecraft landing gear, side bulkheads of spaceships, and rocket fairings [3]. The specific stiffness will increase by seven times in the axial direction with a $3 \%$ increase in the weight of the honeycomb material [4]. In contrast, the specific stiffness is much poorer in the radial direction, owing to the thin-walled structure (less

*Correspondence: hbliu@dlut.edu.cn

Key Laboratory for Precision and Non-traditional Machining Technology of Ministry of Education, Dalian University of Technology, Dalian 116024, China than $0.1 \mathrm{~mm}$ ). Thus, it is difficult to fix the structure and maintain stability using conventional clamping methods [5]. Under the actions of machining with conventional clamping methods, it is common to have certain deformations, which can lead to manufacturing deficiencies, such as high surface roughness, burrs, edge subsiding, and cracking. In that regard, surface qualities, such as surface roughness and surface morphology, are common indexes of the technical quality of a product. Achieving a high surface quality is an important requirement for the mechanical behavior of a component [6-8].

In recent decades, several methods have been developed for fixing honeycomb construction. Double-sided tape bonding is a method that uses double-sided tape to bond the workpiece and the fixture. This method cannot offer enough fixed force to fix the upper surface [9]. The 
vacuum adsorption method [10] is the same as the double-sided tape bonding insofar as the fixed force defect. A method based on magnetic field and friction principles is more stable than the former methods [11]. However, the clamping equipment is too complex, and will increase cost during the machining process. Moreover, it is not easy to accurately control changes in a magnetic field. Although a polyethylene glycol filling method can compensate well for the fixed force defect and can be easily carried out, the residual filler is difficult to clean and pollutes the environment during the heating process [9].

In recent years, ice fixation technology has been utilized to fix the honeycomb construction during the machining process. As with polyethylene glycol, ice could provide enough fixed force and effectively restrain the manufacturing deficiencies, but ice is easier to clean, and causes no pollution. Han et al. [12] developed an ice fixation platform which could maintain the temperature at approximately $-10{ }^{\circ} \mathrm{C}$, to maintain the fit force of the ice. However, the ice was easily melted, owing to the high temperature generated by the cutting process. Using liquid nitrogen as a cryogenic medium could maintain the ice fixation state [13]. This method is easier to perform and more effective at maintaining the ice fixation state, owing to the low temperature of liquid nitrogen $\left(-196^{\circ} \mathrm{C}\right)$.

However, few studies have aimed at improving surface quality by optimizing cutting parameters during the honeycomb machining process, based on ice fixation technology. Honeycomb construction is very sensitive to the cutting parameters, owing to its special structure. Thus, the machining quality is easily affected by cutting parameters. Furthermore, the mechanical properties and reliability of the components are also affected. This study focused on the optimization of the cutting parameters (the spindle speed, feed rate, and cutting depth), for obtaining the best combination of surface roughness and surface morphology. Taguchi's method and an analysis of variance (ANOVA) were used to achieve this purpose.

The paper is organized according to the following sections. First, an overview of the ice fixation method parameter is provided. Then, the experimental details are introduced, i.e., the experimental detail of using Taguchi's method and ANOVA to determine and analyze the optimal cutting parameters in the experiments. Next, the verified experiment is described. Finally, the paper is concluded with a summary of this study.

\section{Analysis of Ice Fixation Machining Technology 2.1 Deformation Analysis}

As a special thin-wall porous structure, each honeycomb cell wall constructed in the honeycomb cutting process is independent. To simplify the analysis, only a single honeycomb structure was extracted for the strain analysis, without regard to support by other honeycomb structures.

During a milling process without ice fixation, there is no support in the interior of the honeycomb structure (Figure 1a). Therefore, without the ice fixation, it is easy for deformities to occur during the machining process. In contrast, ice can provide support forces opposite to the direction of machining (Figure 1b). Accordingly, the deformation can be effectively suppressed by an ice fixation method.

The deformation of a non-ice fixation honeycomb unit can be calculated using Eq. (1) [14]. The deformation of the ice is the ratio of the elongation and side length. After the ice fixation, the deformation of the honeycomb unit approximates to the ice deformation. Moreover, the elongation of the ice is small. Thus, the honeycomb unit does not easily deform under a condition of ice fixation.

$$
\left\{\begin{array}{l}
\varepsilon_{1}=\frac{\sigma(1+\sin \theta) b l^{3} \sin \theta}{12 E I \cos \theta}, \\
\varepsilon_{2}=\frac{\delta}{l},
\end{array}\right.
$$

where $\varepsilon_{2}$ is the deformation of a non-ice fixation honeycomb, $\varepsilon_{2}$ is the deformation of an ice fixation honeycomb, $\sigma$ is the shear force, $E$ is the Young's modulus of the aluminum honeycomb, $I$ is the inertia moment, $\theta$ is the angle between the hypotenuse and the horizontal, $l$ is the side length of the ice and each honeycomb unit, $b$ is the cutting depth, and $\delta$ is the side length change of the ice.

\subsection{Feasibility of Ice Fixation by Simulations}

To verify the feasibility of ice fixation, the cutting processes for both a non-ice fixation honeycomb and an ice fixation honeycomb were simulated using ABAQUS software. These simulations mainly focused on the deformation of the honeycomb. Thus, the cutting tool was
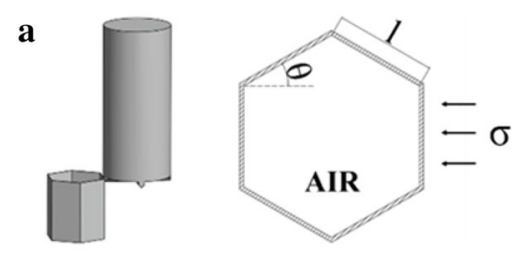

b

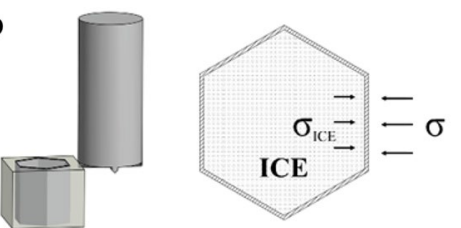

Figure 1 Force analysis of single honeycomb: a model of non-ice fixation, $\mathbf{b}$ model of ice fixation 
Table 1 Johnson-Cook (J-C) material constants for honeycomb [17]

\begin{tabular}{|c|c|c|c|c|c|c|c|}
\hline \multicolumn{8}{|c|}{ Plasticity parameters } \\
\hline$A(\mathrm{MPa})$ & $B(\mathrm{MPa})$ & $C$ & $n$ & $m$ & $\varepsilon$ & $T_{0}\left({ }^{\circ} \mathrm{C}\right)$ & $T_{m}\left({ }^{\circ} \mathrm{C}\right)$ \\
\hline 527 & 575 & 0.017 & 0.72 & 1.61 & 1 & 25 & 635 \\
\hline \multicolumn{8}{|c|}{ Failure parameters } \\
\hline$D_{1}$ & $D_{2}$ & $D_{3}$ & $D_{4}$ & $D_{5}$ & & & \\
\hline 0.110 & 0.572 & -3.446 & 0.016 & 1.099 & & & \\
\hline
\end{tabular}

Table 2 Material constants for ice [18]

\begin{tabular}{lll}
\hline Density $\left(\mathbf{k g} / \mathbf{m}^{\mathbf{3}}\right)$ & Young's modulus $(\mathrm{GPa})$ & Poisson's ratio \\
\hline 900 & 10.79 & 0.33 \\
\hline
\end{tabular}

considered as a rigid body, to simplify the calculation. The workpiece consisted of eight six-sided regular hexagon honeycomb units, and the length of each side was 8 $\mathrm{mm}$. The height of the workpiece was $13 \mathrm{~mm}$. The matrix material of honeycomb was set as aluminum alloy. The material parameters of the workpiece and ice are shown in Table 1 and Table 2. The yield limit of the honeycomb was calculated using Eq. (2). The failure model is shown in Eq. (3) [15]. The ice was considered as a brittle material, and the fracture of the ice was calculated using the brittle cracking model in ABAQUS. The direct stress after cracking was set as $30 \mathrm{MPa}$ [16]. The honeycomb and ice were set to tie, and the same cutting conditions were applied in the two simulations.

$$
\sigma_{\mathrm{h}}=\left(A+B \varepsilon^{n}\right)\left(1+C \ln \varepsilon^{*}\right)\left(1-T^{* m}\right) .
$$

In Eq. (2), $\sigma_{h}$ is the yield limit, $A$ is the material yield strength, $B$ is the strain hardening coefficient, $C$ is the strain rate sensitivity coefficient, $\varepsilon$ is the equivalent plastic strain, $n$ is the strain hardening index, $\varepsilon^{*}$ is the plastic strain rate, $T^{*}$ is the homologous temperature, and $\mathrm{m}$ is the temperature sensitivity coefficient. $A, B, C, n$, and $m$ are constants determined by the material.

$$
\left\{\begin{aligned}
D & =\sum \frac{\Delta \varepsilon}{\varepsilon^{f}}, \\
\varepsilon^{f} & =\left[D_{1}+D_{2} \exp D_{3} \sigma^{*}\right]\left[1+D_{4} \ln \dot{\varepsilon}^{*}\right]\left[1+D_{5} T^{*}\right],
\end{aligned}\right.
$$

where $\Delta \varepsilon$ is the increment of the effective plastic strain, $\varepsilon^{f}$ is the equivalent strain to fracture, $\sigma^{*}$ is the pressurestress ratio, $\dot{\varepsilon}^{*}$ is the strain rate, $T^{*}$ is the homologous temperature, and $D_{1}, D_{2}, D_{3}, D_{4}$, and $D_{5}$ are constants. Fracture is allowed to occur when $D=1.0$.

As shown in Figure $2 \mathrm{a}$, there was an evident deformation of the non-ice fixation honeycomb during the

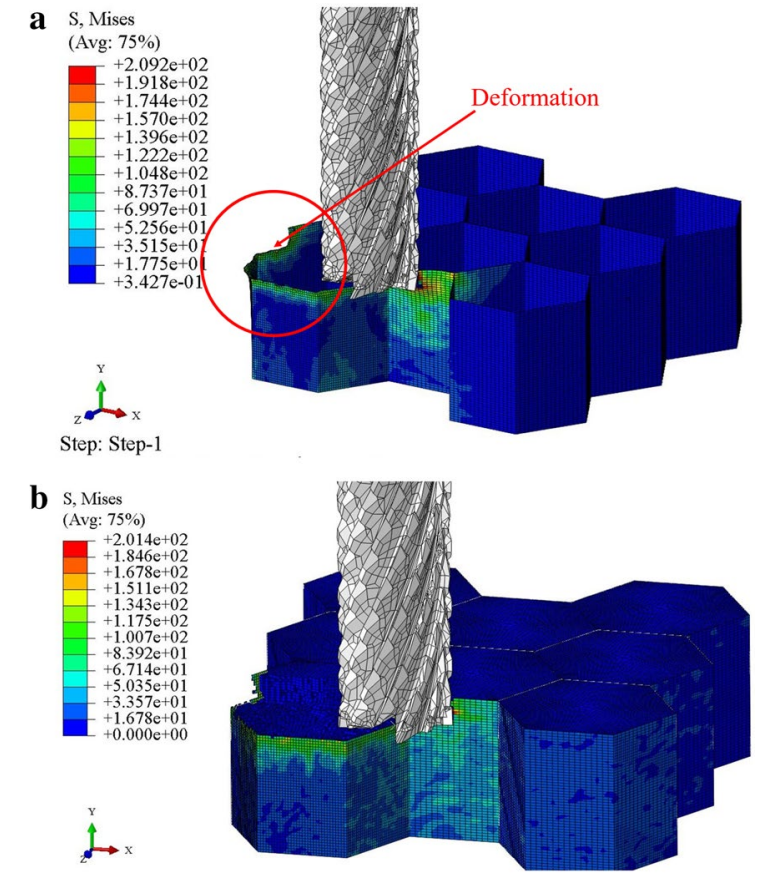

Figure 2 Simulation of cutting process: a non-ice fixation, $\mathbf{b}$ ice fixation (mm)

cutting process. Moreover, a serious machining defect appeared on the machined surface. In contrast, there was little deformation of the honeycomb using the ice fixation method (Figure 2b). Evident defects were not found in the simulation. The results of the simulations indicated that the ice fixation method was effective for honeycomb support during the machining process, as indicated by the results from the deformation analysis. The ice provided enough support forces to the thin wall of the honeycomb, and the deformation was effectively controlled.

\subsection{Setup of the Experiment Platform}

Similar to the case with the polyethylene glycol and magnet powder filling methods, the application of the ice 
fixation method is intended to address the poor specific stiffness in the radial direction of the honeycomb structure during the milling process. Before machining, the honeycomb workpiece was placed in a clamp, water was poured into the clamp until the water surface was suitably covered on the workpiece upper surface of the honeycomb workpiece, and then the entire platform was frozen to transform the water into ice. Thus, the ice was used to support the thin-walled structure of the honeycomb. The ice fixation platform is shown in Figure 3a.

As the experiment was carried out at room temperature, the ice would be inevitably melted. Therefore, to maintain the ice as frozen, liquid nitrogen was continuously sprayed onto the ice, to maintain a sufficiently low temperature. A schematic diagram of the experiment platform is shown in Figure 3b.

\section{Experimental Design}

\subsection{Set-up}

7075 aluminum alloy honeycomb workpieces were used in this experiment. The workpieces were cut into 190

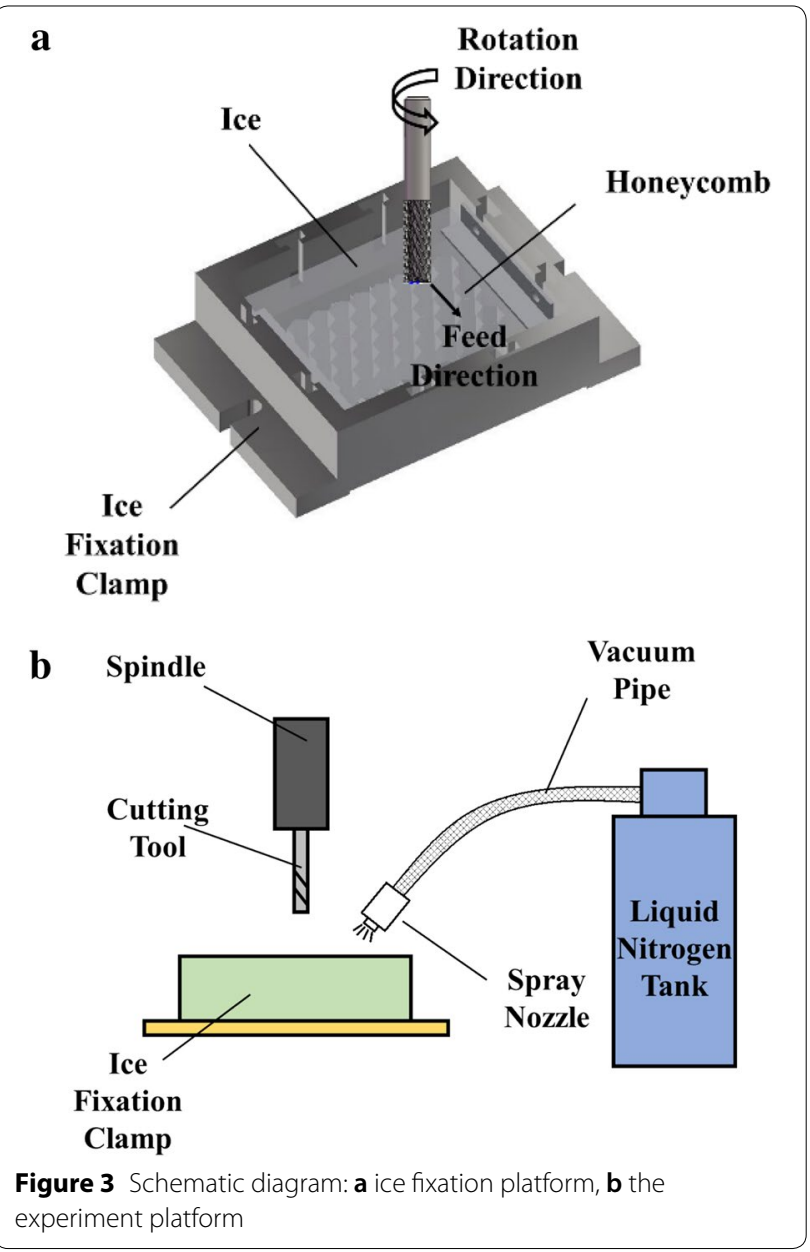

$\mathrm{mm} \times 50 \mathrm{~mm} \times 15 \mathrm{~mm}$ sections. The experiments were performed on a vertical machining center (Changzheng KVC850M, China). A coated cemented carbide with ten ZrN-coated blades (LMT 29-135, Germany) was used, and the diameter was $16 \mathrm{~mm}$. Liquid nitrogen was provided from a liquid nitrogen tank (Tianhai DPL - 175, China). The pressure of the outlet was $1 \mathrm{MPa}$. The platform is shown in Figure 4. The roughness of the machined surfaces was measured by the ZYGO measurement system for the surface profile (NV5000 5022S, USA). A Keyence ultra-depth three-dimensional microscope (VHX-600E, Japan) was used to observe the surface morphology.

\subsection{Taguchi Method}

Conventional experimental methods require a large number of experiments, leading to a waste of resources. Taguchi's method can solve this problem well, as it can minimize variation around a target value $[19,20]$, and offers the opportunity to increase efficiency by optimizing the machining parameters with fewer experiments [21-24]. Taguchi's method analyzes a result through the signal-to-noise ratio ( $\mathrm{S} / \mathrm{N}$ ratio), by creating a number of orthogonal arrays in the design of experiment (DOE).
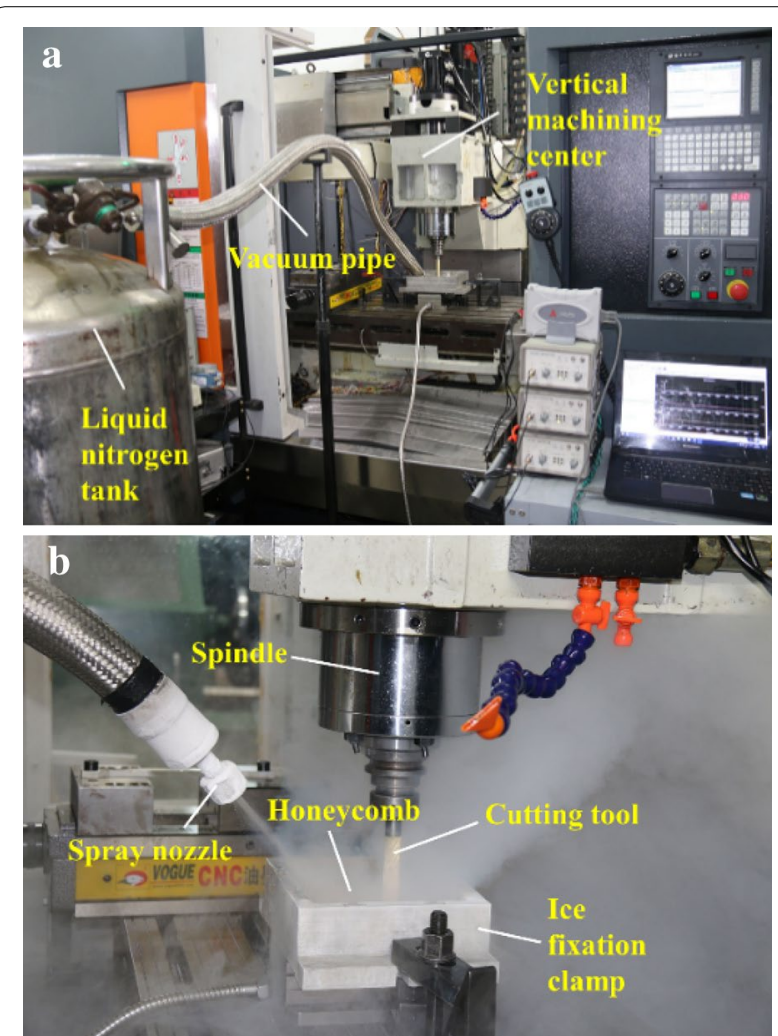

Figure 4 Experiment platform: a general view, b partial view 
Table 3 Design of experiment (DOE)

\begin{tabular}{lllll}
\hline Factor & Level-1 & Level-2 & Level-3 & Level-4 \\
\hline Spindle speed $(\mathrm{r} / \mathrm{min})$ & 2000 & 3000 & 4000 & 5000 \\
Cutting depth $(\mathrm{mm})$ & 0.4 & 0.8 & 1.2 & 1.6 \\
Feed rate $(\mathrm{mm} / \mathrm{min})$ & 50 & 100 & 150 & 200
\end{tabular}

In this study, there are three factors and four levels. The DOE for this study is shown in Table 3.

The $\mathrm{S} / \mathrm{N}$ ratio contributes to preventing variance deviations from the target value, and can be classified into several categories: larger is better, normal is best, and smaller is better. The three categories of the $\mathrm{S} / \mathrm{N}$ ratio were calculated using Eq. (4):

$$
\left\{\begin{array}{l}
\text { Larger is better: } S / N=-10 * \log \left[\sum\left(1 / Y^{2}\right) / n\right], \\
\text { Normal is the best: } S / N=-10 * \log \sum\left(\sigma^{2}\right), \\
\text { Smaller is better: } S / N=-10 * \log \left[\sum\left(Y^{2}\right) / n\right] .
\end{array}\right.
$$

In the above, $Y$ is the observed data, $n$ is the number of experiments, and $\sigma$ is the variance of $Y$.

The highest value of the $\mathrm{S} / \mathrm{N}$ ratio indicates the optimal combination of the parameters in the experiment [2527]. In this work, the $S / N$ ratio of each group is calculated based on the "smaller is better" model, as the purpose of this experiment is to find the minimum surface roughness value.

\subsection{Analysis of Variance (ANOVA)}

The ANOVA was applied to evaluate the importance of each factor. The ANOVA aims to estimate the seriousness of the goal variation caused by the variation of each factor, as observed from the results [28-30]. Three factors were analyzed by ANOVA to determine the influence of each factor on the experimental results. The F-value and $\mathrm{P}$-value were used to estimate the results of the ANOVA. The F-value represents the ratio between the variance of the group and the within-group variance. The larger the F-value, the more significant the equation, and the better the degree of fitting. As a decreasing indicator of the credibility of a result, the P-value indicates the reliability of the result. The larger the P-value, the less we can assume that the association of variables in the sample is a reliable indicator of the correlation of the variables in the population.

\section{Results and Analysis}

\subsection{Cutting Parameters Optimization and Analysis}

According to the DOE, an L16(34) orthogonal array was arranged for the experiment. 16 groups of surface roughness values were measured using the ZYGO measurement system. The results (the roughness average,
Table 4 Experimental results following L16(34) orthogonal array

\begin{tabular}{lllrll}
\hline No. & $\begin{array}{l}\text { Spindle } \\
\text { speed }(\mathbf{r} / \\
\text { min) }\end{array}$ & $\begin{array}{l}\text { Cutting } \\
\text { depth } \\
(\mathbf{m m})\end{array}$ & $\begin{array}{l}\text { Feed rate } \\
(\mathbf{m m} / \mathbf{m i n})\end{array}$ & $\boldsymbol{R}_{\mathrm{a}}(\boldsymbol{\mu m})$ & $\mathrm{S} / \mathrm{N}$ ratio $(\mathrm{dB})$ \\
\hline 1 & 2000 & 0.4 & 50 & 0.480 & 6.3752 \\
2 & 2000 & 0.8 & 100 & 0.552 & 5.1612 \\
3 & 2000 & 1.2 & 150 & 0.602 & 4.4081 \\
4 & 2000 & 1.6 & 200 & 0.612 & 4.2650 \\
5 & 3000 & 0.4 & 100 & 0.519 & 5.6967 \\
6 & 3000 & 0.8 & 50 & 0.368 & 8.6830 \\
7 & 3000 & 1.2 & 200 & 0.555 & 5.1141 \\
8 & 3000 & 1.6 & 150 & 0.586 & 4.6420 \\
9 & 4000 & 0.4 & 150 & 0.450 & 6.9357 \\
10 & 4000 & 0.8 & 200 & 0.569 & 4.8978 \\
11 & 4000 & 1.2 & 50 & 0.288 & 10.8122 \\
12 & 4000 & 1.6 & 100 & 0.416 & 7.6181 \\
13 & 5000 & 0.4 & 200 & 0.561 & 5.0207 \\
14 & 5000 & 0.8 & 150 & 0.507 & 5.8998 \\
15 & 5000 & 1.2 & 100 & 0.497 & 6.0729 \\
16 & 5000 & 1.6 & 50 & 0.320 & 9.8970 \\
\hline
\end{tabular}

hereafter $R_{\mathrm{a}}$, and $\mathrm{S} / \mathrm{N}$ ratio based on $R_{\mathrm{a}}$ ) are shown in Table 4. A main effects analysis was used to analyze the trend of the effect of each factor. The main effects plots for the means and $\mathrm{S} / \mathrm{N}$ ratios of the three factors (spindle speed, feed rate, and cutting depth) in the cutting experiment are shown in Figure 5.

Optimum honeycomb machining conditions require a low value of $R_{\mathrm{a}}$. As shown in Table 4, the $\mathrm{S} / \mathrm{N}$ ratio of No. 11 was outstanding. This indicates that No. 11 is the optimal parameter combination for obtaining the minimum value of $R_{\mathrm{a}}$ in this orthogonal array. The main effect plots show the influence of each factor on the results of the experiment. In the main effect plots for the means and $\mathrm{S} / \mathrm{N}$ ratios, the levels of the cutting parameters ensured that the process would not deviate when its target was level $3(4000 \mathrm{r} / \mathrm{min})$ of the spindle speed and level 1 $(50 \mathrm{~mm} / \mathrm{min})$ of the feed rate. The cutting depth had little effect on the results, according to the main effect plots of the honeycomb cutting experiments.

Table 5 shows the ANOVA analysis of the experiment. According to the ANOVA analysis, the F-value and P-value were calculated, to verify the significance of each factor. The larger the F-value, the greater the influence of the factor on the result. In the case of the surface roughness, the feed rate was the most significant factor, based on the F-value in the ANOVA analysis. The spindle speed was in second place. As mentioned above, the cutting depth had minimal impact. The analysis was performed for a significance level of $\alpha=0.05$ (confidence 

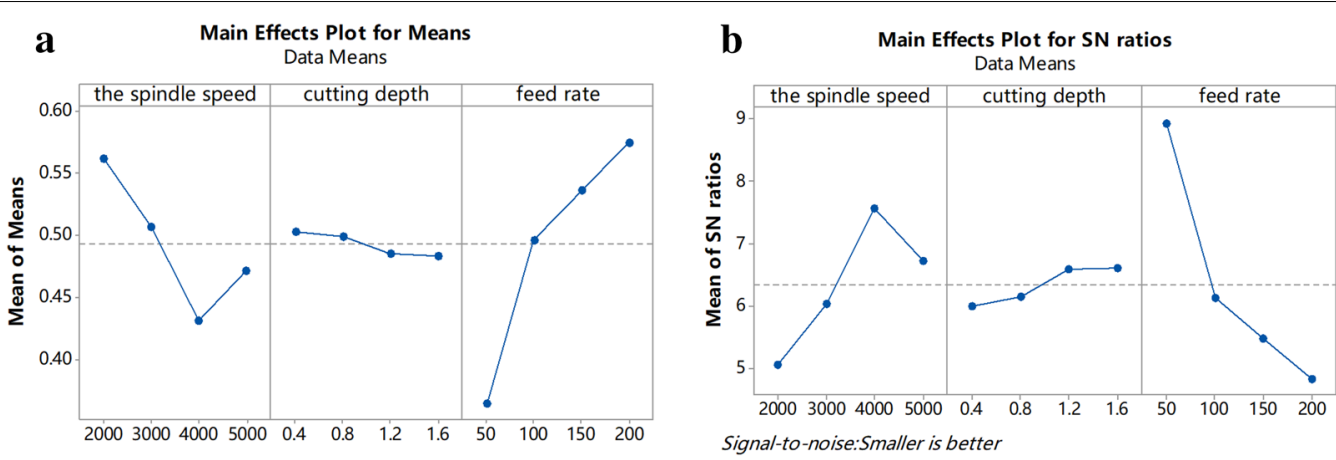

Figure 5 Main effects plot: a mean effects plot, b signal-to-noise $(S / N)$ ratio plot

Table 5 Analysis of variance (ANOVA)

\begin{tabular}{llllll}
\hline Factor & $\begin{array}{l}\text { Degree } \\
\text { of freedom }\end{array}$ & Seq SS & Adj MS & F-value & P-value \\
\hline Spindle speed & 3 & 0.036943 & 0.012314 & 7.17 & 0.021 \\
Cutting depth & 3 & 0.001089 & 0.000363 & 0.21 & 0.885 \\
Feed rate & 3 & 0.100486 & 0.033495 & 19.49 & 0.002 \\
Error & 6 & 0.010309 & 0.001718 & & \\
Total & 15 & 0.148828 & & & \\
\hline
\end{tabular}

level of 95\%). Thus, the P-value was set at 0.05. As judged by the P-value, a factor that exceeds 0.05 is insignificant. It was verified that the cutting depth had little effect on the results by examining the P-value. In contrast, the other two factors were significant in this experiment. In conclusion, the feed rate and spindle speed were the most significant factors during the honeycomb machining process.

However, the surface roughness is not the only evaluation criterion for machining. The surface morphology is also important in the honeycomb machining process. A Keyence ultra-depth three-dimensional microscope was used to observe the surface morphology of the orthogonal arrays. Although the ice fixation method greatly improves the machining quality of a honeycomb, there is still surface morphology deterioration when the cutting parameters are unsuitable. In that regard, Figure 6 shows a typical deterioration; cracking defects and burr phenomena occurred, owing to inappropriate cutting parameters. In contrast, the surface morphology of the No. 11 group was evidently superior to the others. There was no evident surface morphology deterioration detected in the picture of the No. 11 group (Figure 7).

As combined with the results of surface roughness and surface morphology, the best quality of honeycomb machining was obtained with the parameters of the No. 11 group $(4000 \mathrm{r} / \mathrm{min}$ spindle speed, $50 \mathrm{~mm} / \mathrm{min}$ feed

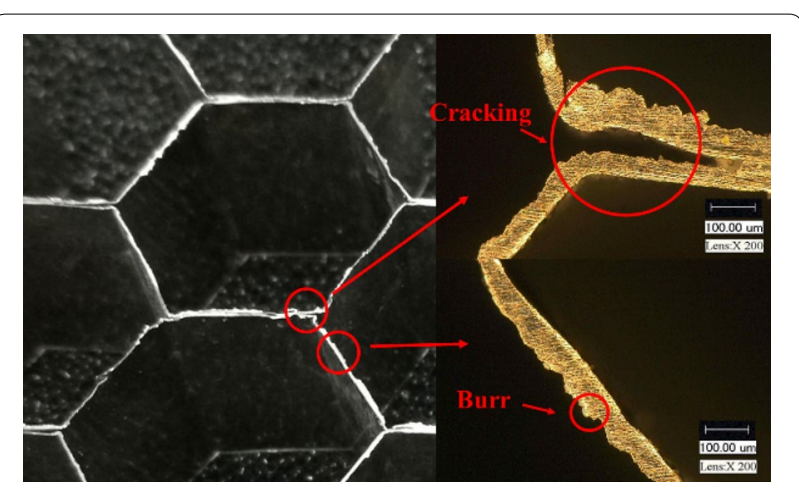

Figure 6 Typical surface morphology deterioration

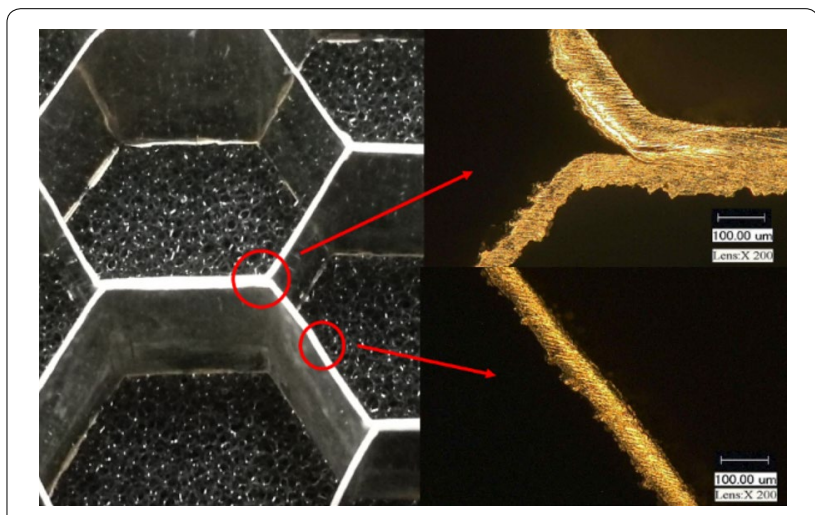

Figure 7 Surface morphology of the No. 11 group

rate, and $1.2 \mathrm{~mm}$ cutting depth). According to the analysis of the Taguchi method and ANOVA, the feed rate had the greatest impact on surface quality, the spindle speed was the second most-influential factor, and the cutting depth was insignificant.

Owing to the deformation inhibition from the ice fixation method, the cutting depth has the least influence on the experiment. The honeycomb is a typical thin-walled 
structure, and it is sensitive to vibration (although the ice fixation provides a support force). With rising spindle speed, the vibration increases. The vibration reduces the binding capacity between the ice and honeycomb. Moreover, the ice is a brittle material, and is fragile under vibration. Therefore, when the spindle speed reached $5000 \mathrm{r} / \mathrm{min}$, the surface roughness was higher than $4000 \mathrm{r} / \mathrm{min}$. With an increasing feed rate, the strength of the ice could not support the cutting force, and thus the occurrence of extrusion deformations rose. As a result, it was easier to induce manufacturing deficiencies.

\subsection{Experiments by Optimum Cutting Parameters}

A verified experiment was performed with the optimum cutting parameters according to the analysis of the Taguchi method and ANOVA, to validate the conclusions obtained in the above research. The cutting tool in this verified experiment was replaced by a KYOCERA, SGS series,43MAPF 44631 D12, for eliminating the cutting tool influencing factor. The workpiece is shown in Figure 8 .

The experimental results proved the validity of the cutting parameters. After optimization, the value of $R_{\mathrm{a}}$ is $0.218 \mu \mathrm{m}$, which is superior to the value from workpiece machining without optimization (Figure 9). There is no

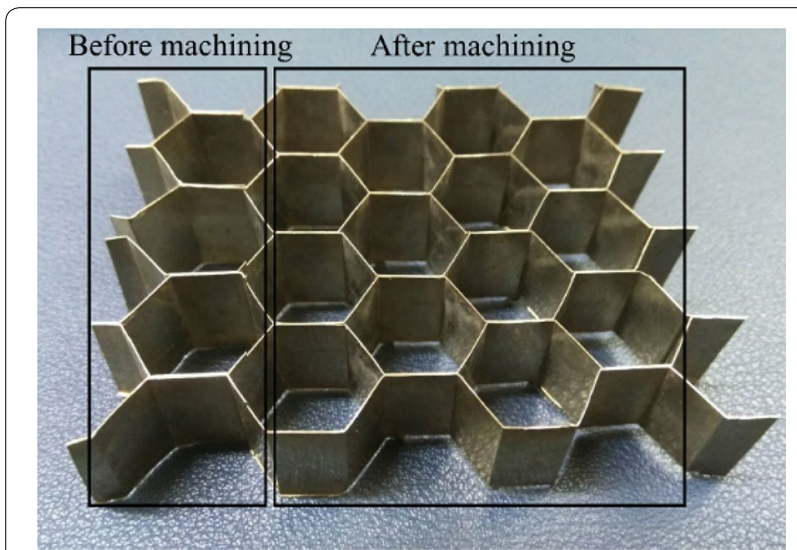

Figure 8 Workpiece in the confirmation experiment

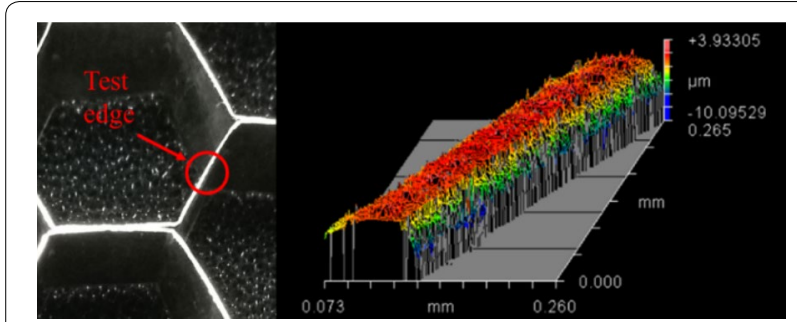

Figure 9 Surface roughness of the workpiece without optimization

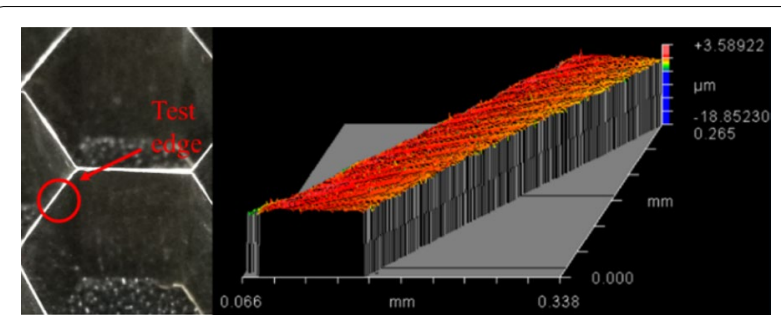

Figure 10 Surface morphology of verified experimental workpiece

surface morphology deterioration in the verified experimental workpiece (Figure 10). Both the surface roughness and surface morphology proved that the optimum cutting parameters in the above research were suitable for machining an aluminum honeycomb using an ice fixation method.

\section{Conclusions}

In this study, a deformation analysis and simulations were conducted to verify the feasibility of an ice fixation method. Taguchi's method and ANOVA were applied to evaluate the effects of cutting parameters on the surface roughness and surface morphology in machining an aluminum alloy honeycomb with ice fixation. The optimum cutting parameters were determined for minimizing the $R_{\mathrm{a}}$ and improving the surface morphology.

The most optimal results in the orthogonal arrays were obtained when the feed rate was $50 \mathrm{~mm} / \mathrm{min}$, cutting depth was $1.2 \mathrm{~mm}$, and spindle speed was $4000 \mathrm{r} /$ min. For minimizing the surface roughness, the feed rate was the most significant factor, followed by spindle speed. The cutting depth was insignificant in this study. After optimization, the surface roughness value was better than that without optimization. Moreover, there was no surface morphology deterioration.

This research could be applied to improve machining quality, under the conditions of "green" environmental protection in engineering applications. Moreover, this approach can avoid waste and improve the stability of the components. The cutting direction and cutting path should be considered in further research aimed towards curved surfaces in engineering applications.

\footnotetext{
Authors' Contributions

YW provided fundamental ideas and all support conditions of this paper. YG was in charge of the trial and wrote the manuscript. $\mathrm{HL}$ and $\mathrm{KL}$ conducted proof reading and made some critical revisions. LH and JW assisted the trial and simulations. All authors read and approved the final manuscript.
}

\section{Authors' Information}

Yongqing Wang, born in 1969, is currently a professor and a PhD candidate supervisor at Key Laboratory for Precision and Non-traditional Machining Technology of Ministry of Education, Dalian University of Technology, China. He 
received his PhD degree from Dalian University of Technology, China, in 2002. His title is "the Yangtze River scholar Professor".

Yongquan Gan, born in 1986, is currently a PhD candidate at Key Laboratory for Precision and Non-traditional Machining Technology of Ministry of Education Dalian University of Technology, China. He received his master degree from Dalian Jiaotong University, China, in 2013. His research interest is cryogenic machining.

Haibo Liu, born in 1983, a professor and a PhD candidate supervisor at Key Laboratory for Precision and Non-traditional Machining Technology of Ministry of Education, Dalian University of Technology, China. He received his PhD degree from Dalian University of Technology, China, in 2012.

Lingsheng Han, born in 1992, is currently a PhD candidate at Key Laboratory for Precision and Non-traditional Machining Technology of Ministry of Education Dalian University of Technology, China.

Jinyu Wang, born in 1993, he received his master degree from Dalian University of Technology, China, in 2019.

Kuo Liu, born in 1983, a professor at Key Laboratory for Precision and Nontraditional Machining Technology of Ministry of Education, Dalian University of Technology, China. He received his PhD degree from Northeastern University, China, in 2010

\section{Funding}

Supported by National Key Research and Development Program of China (Grant No. 2019YFB2005400), National Natural Science Foundation of China (Grant No. U1608251), Open project of State Key Laboratory of high performance complex manufacturing (Grant No. Kfkt2016-05) and Changjiang Scholar Program of Chinese Ministry of Education (Grant No. T2017030).

\section{Competing Interests}

The authors declare no competing financial interests.

Received: 27 June 2019 Revised: 26 December 2019 Accepted: 13 February 2020

Published online: 27 February 2020

\section{References}

[1] M Ding, P L Zhang, ZY Zhang, et al. A novel assembly technology of aluminum alloy honeycomb structure. The International Journal of Advanced Manufacturing Technology, 2010, 46(9-12): 1253-1258.

[2] PR Jeyakrishnan, K K S K Chockalingam, R Narayanasamy. Studies on buckling behavior of honeycomb sandwich panel. The International Journal of Advanced Manufacturing Technology, 2013, 65(5-8): 803-815.

[3] M Jaafar, S Atlati, H Makich, et al. A 3D FE modeling of machining process of Nomex ${ }^{\circledR}$ honeycomb core: Influence of the cell structure behaviour and specific tool geometry. Procedia CIRP, 2017, 58: 505-510.

[4] KX Qiu, W W Ming, L F Shen, et al. Study on the cutting force in machining of aluminum honeycomb core material. Composite Structures, 2017, 164: 58-67.

[5] I G Masters, K E Evans. Models for the elastic deformation of honeycombs. Composite Structures, 1996, 35(4): 403-422

[6] M Nalbant, H Gökkaya, G Sur. Application of Taguchi method in the optimization of cutting parameters for surface roughness in turning. Materials \& Design, 2007, 28(4): 1379-1385

[7] P Nieslony, G M Krolczyk, SWojciechowski, et al. Surface quality and topographic inspection of variable compliance part after precise turning. Applied Surface Science, 2018, 434: 91-101.

[8] A M Khorasani, I Gibson, M Goldberg, et al. Investigation on the effect of cutting fluid pressure on surface quality measurement in high speed thread milling of brass alloy (C3600) and aluminium alloy (5083). Measurement, 2016, 82: 55-63.
[9] C Ma, F J Liu. Research progress in processing technology of honeycomb materials. Aeronautical Manufacturing Technology, 2016(03): 48-54. (in Chinese)

[10] M D A A Prakash, V L J Guptha, R S Sharma, et al. Influence of cell size on the core shear properties of FRP honeycomb sandwich panels. Materials and Manufacturing Processes, 2012, 27(2): 169-176.

[11] Y L Ke, G Liu. Attractive fixture system based on magnetic field and friction force for numerically controlled machining of paper honeycomb core. Journal of Manufacturing Science and Engineering, Transactions of the ASME, 2005, 127(4): 901-906.

[12] B Z Han, KX Qiu, Q L An, et al. Experimental research on processing honeycomb material technology with ice fixation. Tool Engineering, 2017, 51(12): 14-18. (in Chinese)

[13] F B Wang, J K Liu, L L Li, et al. Green machining of aluminum honeycomb treated using ice fixation in cryogenic. The International Journal of Advanced Manufacturing Technology, 2017, 92(1-4): 943-952.

[14] L J Gibson, M F Ashby, G S Schajer, et al. The mechanics of two-dimensional cellular materials. Proceedings of the Royal Society of London Series A-Mathematical Physical and Engineering Sciences, 1982, 382(1782): 25-42.

[15] G R Johnson, W H Cook. Fracture characteristics of three metals subjected to various strains, strain rates, temperatures and pressures. Engineering Fracture Mechanics, 1985, 21(1): 31-48.

[16] M A Rist, S J Jones, T D Slade. Microcracking and shear fracture in ice. International Glaciological Society, 1994, 19: 131-137.

[17] W Jomaa, O Mechri, J Lévesque, et al. Finite element simulation and analysis of serrated chip formation during high-speed machining of AA7075-T651 alloy. Journal of Manufacturing Processes, 2017, 26: 446-458.

[18] F B Wang, Y Q Wang, J S Wang, et al. Milling of Ti alloy honeycomb treated by ice fixation in cryogenic. Machining Science and Technology, 2018: 1-20.

[19] STripathy, D K Tripathy. Multi-response optimization of machining process parameters for powder mixed electro-discharge machining of $\mathrm{H}-11$ die steel using grey relational analysis and topsis. Machining Science and Technology, 2017, 21(3): 362-384.

[20] S Debnath, M M Reddy, Q S Yi. Influence of cutting fluid conditions and cutting parameters on surface roughness and tool wear in turning process using Taguchi method. Measurement, 2016, 78: 111-119.

[21] M Mia, N R Dhar. Optimization of surface roughness and cutting temperature in high-pressure coolant-assisted hard turning using Taguchi method. The International Journal of Advanced Manufacturing Technology, 2017, 88(1-4): 739-753.

[22] P S Bilga, S Singh, R Kumar. Optimization of energy consumption response parameters for turning operation using Taguchi method. Journal of Cleaner Production, 2016, 137: 1406-1417.

[23] S Karabulut. Optimization of surface roughness and cutting force during AA7039/Al2O3 metal matrix composites milling using neural networks and Taguchi method. Measurement, 2015, 66: 139-149.

[24] M Sarıkaya, A Güllü. Multi-response optimization of minimum quantity lubrication parameters using Taguchi-based grey relational analysis in turning of difficult-to-cut alloy Haynes 25. Journal of Cleaner Production, 2015, 91: 347-357

[25] Y Zheng, F Gu, Y Ren, et al. Improving mechanical properties of recycled polypropylene-based composites using Taguchi and ANOVA techniques. Procedia CIRP, 2017, 61: 287-292.

[26] C Li, Q Xiao, YTang, et al. A method integrating Taguchi, RSM and MOPSO to CNC machining parameters optimization for energy saving. Journal of Cleaner Production, 2016, 135: 263-275.

[27] U A Dabade, S S Karidkar. Analysis of response variables in WEDM of Inconel 718 using Taguchi technique. Procedia CIRP, 2016, 41: 886-891.

[28] A S Canbolat, A H Bademlioglu, N Arslanoglu, et al. Performance optimization of absorption refrigeration systems using Taguchi, ANOVA and Grey Relational Analysis methods. Journal of Cleaner Production, 2019, 229 874-885.

[29] A H Bademlioglu, A S Canbolat, N Yamankaradeniz, et al. Investigation of parameters affecting Organic Rankine Cycle efficiency by using Taguchi and ANOVA methods. Applied Thermal Engineering, 2018, 145: 221-228.

[30] M Mia, M A Khan, N R Dhar. Study of surface roughness and cutting forces using ANN, RSM, and ANOVA in turning of Ti-6Al-4V under cryogenic jets applied at flank and rake faces of coated WC tool. The International Journal of Advanced Manufacturing Technology, 2017, 93(1-4): 975-991. 